\title{
A multi-criteria analysis of sewer monitoring methods for locating pipe blockages and manhole overflows
}

\author{
(D) Yelbek Utepov ${ }^{1}$, (D) Alizhan Kazkeyever,*, (D)Aleksej Aniskin ${ }^{1}$ \\ ${ }^{1}$ Department of Structural Engineering, L.N. Gumilyov Eurasian National University, 2 Satpayev str., Nur-Sultan, \\ Kazakhstan \\ ${ }^{2}$ Department of Civil Engineering, University North, Varaždin, Croatia \\ *Correspondence: alizhan7sk@gmail.com
}

\begin{abstract}
This article is devoted to the aggregation of existing methods for monitoring sewerage systems into a single symbiosis, in particular methods for identifying the locations of clogged pipes and manhole overflows. Clogging of sewers is a frequent problem in large cities, entailing overfilling of manholes with sewage and disruption of the whole sewage system. Today, there are several methods for monitoring sewers: visual, acoustic and laser. Each method is represented by a wide range of devices with different characteristics and applications. The analysis identified the main technical and economic characteristics for each solution presented. Then, on the basis of the data obtained, a multi-criteria analysis was made according to several parameters: measurement accuracy, maximum diameter of the inspected pipe, type of pipe, cost. For the most objective selection, each parameter was given its own weight, and all parameters were normalized for their objective comparison. On this basis, all solutions were sorted by maximum values for each criterion, taking into account the selection by weights. As a result of the multicriteria analysis, five combinations of solutions were built, including several monitoring methods.
\end{abstract}

Keywords: multicriteria analysis, sewer sensors, pipeline inspection, sewage clogging, siltation, solution aggregation.

\section{Introduction}

Despite the fact that sewers are hidden from view, they play an important role in the life of every person. In existing terminology, the sewage system should be understood as technical facilities and networks of pipelines designed for the collection and disposal of solid and liquid waste products of human activity, domestic and rainwater generated in settlements for the purpose of cleaning them from contamination [1].

With the increasing level of urbanization, the load on the sewage system inevitably increases, and as a consequence, there is its increased wear and tear and violations in the work. Typical manifestations of such loads are overfilling of sewer manholes, clogging of pipelines due to their silting, accumulation of dangerous gases for humans at the bottom of cells, as well as unpleasant odor [2]. Such a malfunctioning sewer system leads to many costs. Direct costs include the cost of inspecting the piping and repairing problems. Indirect costs include the costs associated with removing the consequences of clogging: cleaning of streets and municipal property. All this not only interferes with the normal functioning of the urban system, but also affects the lives and comfort of people, which belongs to the category of social costs [3]. In addition, floods and rainwater overflowing into sewage drains pose a threat, as a result of which this water can mix with sewage and enter open water bodies. Urban wastewater is known to contain many hazardous substances and pathogenic bacteria, making it unacceptable to overfill wells with this water [4].

The trend of urbanization around the world continues to grow. Thus, today more than 4 billion people live in cities. Moreover, the number of urban dwellers is expected to reach about 7 billion by 
2050, which means that the load on sewers will only increase [5]. Such conditions necessitate competent management of the existing assets of pipe systems, one of the most important factors of which is condition assessment.

There are many solutions aimed at monitoring and controlling the current state of sewers [69]. At the same time, each technology has its advantages and disadvantages, which should be considered when choosing. Based on world practice, all methods can be divided into traditional and modern [10]. The presence of a sewer blockage is usually established and eliminated by the fact of its occurrence. This is the easiest approach in application, which does not require serious costs for equipment, but it is not suitable in large cities with a complex system of pipelines due to the high labor intensity of the process. Also, based on the essence of this method, the probability of flooding wells and clogging of pipelines cannot be predicted [11]. Another approach is using special float sensors, indicating about exceeding of permissible liquid level in a well [12]. In this case human participation in monitoring is minimal; however, effectiveness of the method can be reduced in winter time when water in the well will freeze. These methods are considered to be traditional and the most commonly used in a large number of cities. Modern solutions offer a more flexible system for monitoring the state of sewers through the use of a set of different sensors and technologies [13-14]. Thanks to them, it is possible to predict and prevent failures in the pipeline system, and most importantly - without direct human intervention, that is, remotely. Such solutions include: visual methods using cameras; acoustic, using ultrasonic and acoustic sensors; laser; temperature and others. It is worth noting that not all of them are equally suitable and effective for use in different conditions. The diameter of the pipe, the number of its turns and the size of the well play an important role in choosing one or another method of monitoring. The most common types of pipes include:

- Self-flow lines - inclined sewage pipes that transport wastewater under the action of gravity;

- Mainlines - pressure pipelines used for pumping and transporting wastewater;

- Drainage (diversion) canals - pipelines designed to transport wastewater from buildings to mainlines.

Depending on the type and purpose of the pipes, the material from which they are made can also vary. These days, gravity lines are made of plastic, cast iron or reinforced concrete. Large mainlines are more often made of ferrous metals such as cast iron or steel, while small ones are made of PVC and HDPE plastic. PVC and HDPE plastic are also commonly used for bends [15].

Due to the differences in the size of devices and equipment, it is also worth considering the diameter of the pipes. For example, too large a pipe can interfere with the visual monitoring of its internal condition due to the technical limitations of the camera and poor lighting. As in the case of traditional solutions, modern methods of sewer monitoring are not without disadvantages. The main disadvantage is the impossibility of obtaining objective data using only a particular method or sensor. To get a complete picture of the condition of sewers requires the use of multiple solutions and technologies.

Unfortunately, sometimes the wrong selection of monitoring solutions leads to unreliability of the information obtained. For example, using only visual monitoring methods, it is impossible to obtain digital data on volumes. If we talk about traditional methods, float sensors allow an objective assessment of the situation through detailed data on the water level, but may be useless when it freezes, consequently the float sensor will be fixed in a certain position and will transmit incorrect measurements. Theoretically, in a particular case, both methods listed above could be combined into a single system, where each component would solve the disadvantage of the other. Such a symbiosis of solutions can be aggregated based on the conditions and objectives of a particular sewer system based on a variety of other methods and technologies. In this regard, the question of careful analysis of the technical and economic parameters of each solution to implement the most optimal selection of the combination into a single symbiosis is relevant.

In this paper, the object of the study are methods and technologies aimed at detecting siltation, clogging, overfilling of sewage wells, collectors and pipelines. 
The purpose of this paper is to aggregate existing methods for monitoring sewerage systems into a single symbiosis.

\section{Methods}

The measures to monitor the condition of sewers include a wide range of works: detection of leaks, corrosion sites, cracks, deformations, as well as blockages. For the convenience of further aggregation, technical and economic parameters of existing solutions and technologies for monitoring were collected, their key criteria (parameters) were established and compared, as well as a multicriteria analysis was performed.

\subsection{Data collection}

A summary of existing solutions for sewer monitoring is shown in Table 1.

Table 1 - Methods and technologies for sewer monitoring

\begin{tabular}{ccc}
\hline Method & $\begin{array}{c}\text { Applied devices, sensors } \\
\text { and technologies }\end{array}$ & Short description \\
\hline $\begin{array}{c}\text { Human } \\
\text { inspection }\end{array}$ & - & $\begin{array}{c}\text { Visual inspection of the internal condition of wells, } \\
\text { collectors with the direct participation of a person }\end{array}$ \\
\hline $\begin{array}{c}\text { Visual } \\
\text { observation }\end{array}$ & $\begin{array}{c}\text { Cameras, camera probes, } \\
\text { zoom cameras, digital } \\
\text { scanners }\end{array}$ & $\begin{array}{c}\text { Using different types of cameras to obtain visual } \\
\text { images, with which you can assess the condition of } \\
\text { the sewer }\end{array}$ \\
\hline $\begin{array}{c}\text { Acoustic } \\
\text { method }\end{array}$ & $\begin{array}{c}\text { Sonars, ultrasonic level } \\
\text { meters }\end{array}$ & Using sound waves to detect defects, presence of \\
clogging in the pipeline
\end{tabular}

Visual Monitoring. Monitoring with cameras is one of the most common methods of assessing the internal condition of pipes (Figure 1). It provides an opportunity to inspect the sewer when the size of the pipeline is too small or the working conditions are dangerous for humans [16-17]. This approach to monitoring allows identifying almost all required parameters of the state of the sewer: the presence of cracks, the formation of silt and other contaminants, the formation of clogging and overfilling of the manhole. The main disadvantages of such a solution are that the camera system alone cannot provide an objective assessment of the internal condition and requires an operator who could draw conclusions based on the visual information obtained. Also, because of the way the cameras work and the nature of the method, pipe surfaces can only be inspected above the water level, which also limits the scope of their application. In general, this method can be used as the basic one for sewerage monitoring due to providing the most complete range of data used in inspection and its economic efficiency; however, it is recommended to use it as an auxiliary tool.

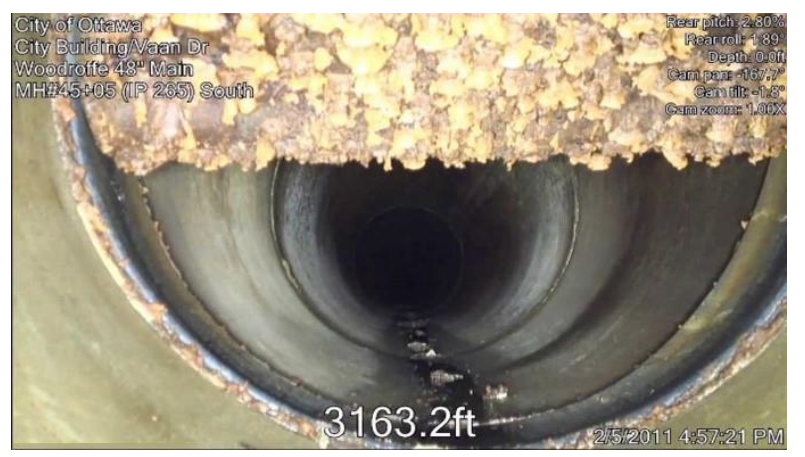

Figure 1 - Example of internal pipe condition monitoring with cameras 
The technology of visual observation of internal condition of pipelines is represented by a wide range of devices: zoom cameras, digital scanners, mobile cameras. Each type of cameras is also represented by a variety of devices from different manufacturers, each of which has its own characteristics of operation (Table 2).

Table 2 - Brief information about zoom cameras

\begin{tabular}{cc}
\hline Pipe type & Self-flow lines \\
\hline Piping material & Any \\
\hline Pipe size & $\sim$ up to $150 \mathrm{~mm}$ \\
\hline Detectable defects & Leaks, cracks, siltation, general condition of the pipe surface \\
\hline Advantages & Ease of use, relatively high efficiency and low cost \\
\hline Disadvantages & $\begin{array}{c}\text { The need for an operator, restrictions on the type and size of the } \\
\text { pipeline, limitations on the resolution of the lens, the likelihood of } \\
\text { missing hidden underwater defects }\end{array}$ \\
\hline
\end{tabular}

Digital scanners. Digital scanners are a system of two cameras pointing in opposite directions and taking wide-angle photos of the inner space of the pipe (Figure 2). [18-19]. During the initiation of the inspection, the cameras simultaneously begin to capture images, which are then stitched together into a single whole image with a 360-degree view. In addition to dual, there are also scanners with a single camera having a wide angle of image capture. The principle of operation in this case is identical to dual-camera scanners. The advantage of digital scanning is that the possibility of missing a defect is minimized. In contrast to zoom cameras, where fixation of defects is carried out by the operator controlling the camera rotation, with digital scanning an overall picture of the whole inspected surface is taken [20]. As a result of scanning a digital model can be obtained, on the basis of which digital measurements will be carried out. It is also possible to sweep the image into a single plane. Thanks to this the probability that the operator will not point the camera to the necessary part of the pipe and will miss a defect is reduced to zero.

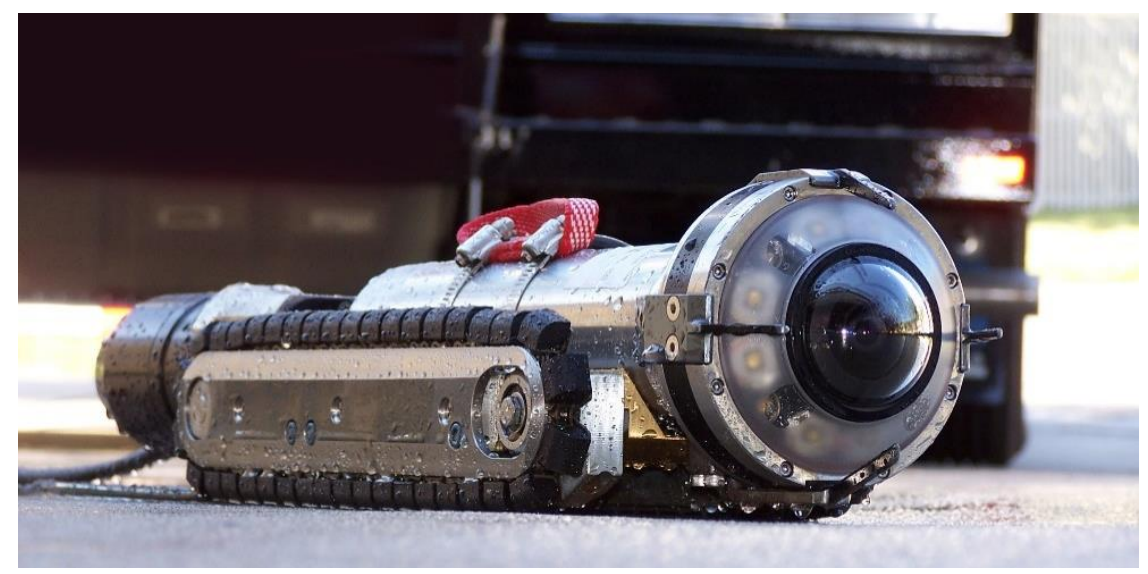

Figure 2 - Digital scanner on a crawler

Digital scanners have similar limitations to zoom cameras. Because the entire surface of the pipe is being scanned, it needs to be dry. Access to some pipes is also a significant limitation. Digital scanning technology is mostly used for gravity flow pipe diameters from $150 \mathrm{~mm}$ up to $1500 \mathrm{~mm}$ due to its easy accessibility. A brief summary of the zoom cameras is presented in Table 3.

Table 3 - Brief information about digital scanners

\begin{tabular}{cc}
\hline Pipe type & Self-flow lines, limited applicability for main and service pipelines \\
\hline Piping material & Any \\
\hline Pipe size & $150-1500 \mathrm{~mm}$ \\
\hline Detectable defects & Leaks, cracks, siltation, general condition of the pipe surface \\
\hline
\end{tabular}


Advantages High efficiency, higher accuracy than conventional cameras, the ability to obtain a digital model of the section of the pipeline, the possibility of digital measurement of defects

Disadvantages The cost of the equipment is higher compared to conventional cameras, the inability to work in water

Acoustic method. The essence of the acoustic method is the use of special measuring devices - sonars, recording the reflection of the ultrasonic signal [6]. They consist of a scanning head, connected with a wire to the processor and monitor. The devices emit an ultrasonic wave, which reaches the area where the defect is observed. When the signal reaches the walls of the pipeline or any other obstacle, the sonar head records its reflections. The reflection varies depending on the material and working medium, allowing the type of surface and therefore the type of contamination, its hardness, to be accurately determined. This method is suitable for detecting various defects in pipelines, including blockages [21]. Also, the time spent on sending and receiving the signal can be used to determine the distance between the sonar head and the pipe wall. From this data, a detailed profile of the pipe can be created, which can then be used for other purposes (Figure 3). In complex branched pipelines, sonars can be mounted on a self-propelled cart.

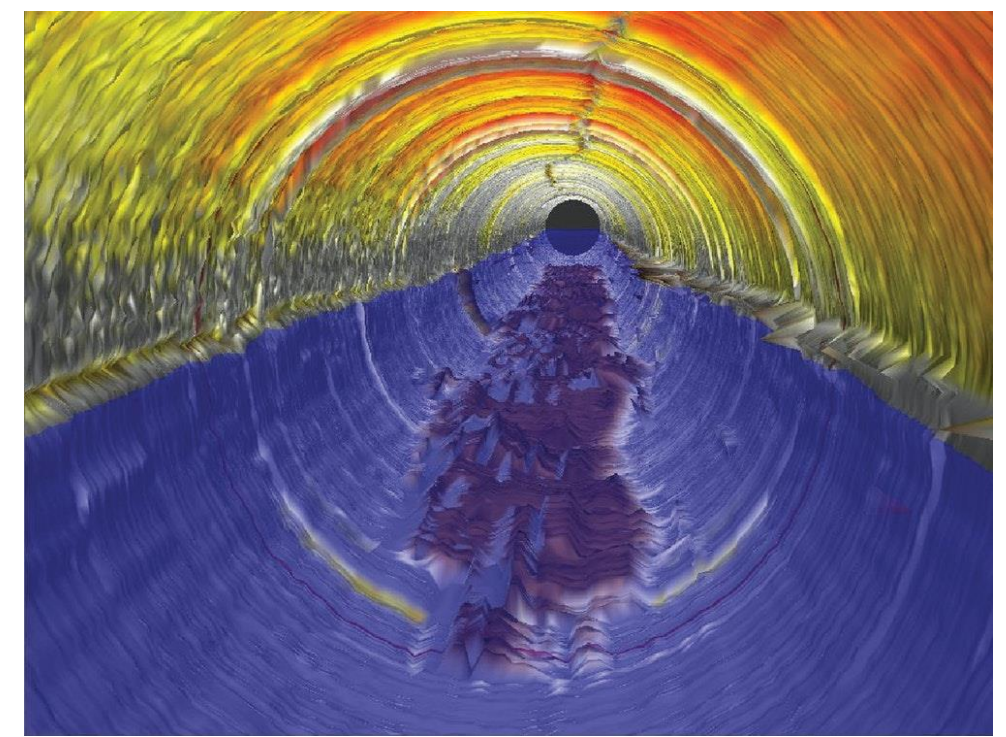

Figure 3 - Example of a pipe profile obtained with the sonar

A significant advantage of the acoustic monitoring method is that it is highly accurate and versatile. When using this method, not only blockages, but also cracks, deflections of pipe walls, corrosion and cavities can be detected. However, it should be taken into account that some defects may be hidden by a layer of grease deposits and debris, so that their detection will be impossible. Also, as described above, signal reflection and reception are affected by the environment in which the sonar will be located. Sonars can work both in dry environment and in water, but the survey cannot be performed in partially filled pipes. This problem is partially solved by installing cameras that record the condition of the pipes in the area above the water level. Brief description of existing sonars on the market is presented in Table 4.

Table 4 - Sonar summary

\begin{tabular}{cccc}
\hline Device & Pipe diameter & Type of pipe & Features \\
\hline A-SIS & up to $300 \mathrm{~mm}$ & Any & Includes sonar and camera \\
\hline Envirosight & up to $300 \mathrm{~mm}$ & Self-flow lines & $\begin{array}{c}\text { Addition to video surveillance } \\
\text { system }\end{array}$ \\
\hline
\end{tabular}




\begin{tabular}{cccc}
\hline PipeEye & up to $250 \mathrm{~mm}$ & $\begin{array}{c}\text { Mainline, Self- } \\
\text { flow lines }\end{array}$ & \\
\hline RVS2 & up to $250 \mathrm{~mm}$ & Any & \\
\hline Sonar Profiler System & up to $300 \mathrm{~mm}$ & Any & $\begin{array}{c}\text { Includes sonar and camera in } \\
\text { semi-submerged pipes }\end{array}$ \\
\hline $\begin{array}{c}\text { Sonar Sewer Profiling } \\
\text { Attachment }\end{array}$ & up to $900 \mathrm{~mm}$ & $\begin{array}{c}\text { Mainline, Self- } \\
\text { flow lines }\end{array}$ & \\
\hline $\begin{array}{c}\text { Sonar Sweep } \\
\text { Attachment }\end{array}$ & up to $900 \mathrm{~mm}$ & $\begin{array}{c}\text { Mainline, Self- } \\
\text { flow lines }\end{array}$ & Includes sonar and camera \\
\hline
\end{tabular}

Laser method. The essence of the laser method of monitoring consists in creating an internal profile of the pipeline wall using special laser devices that project laser lines (Figure 4). This method is also called laser profilometry [22].

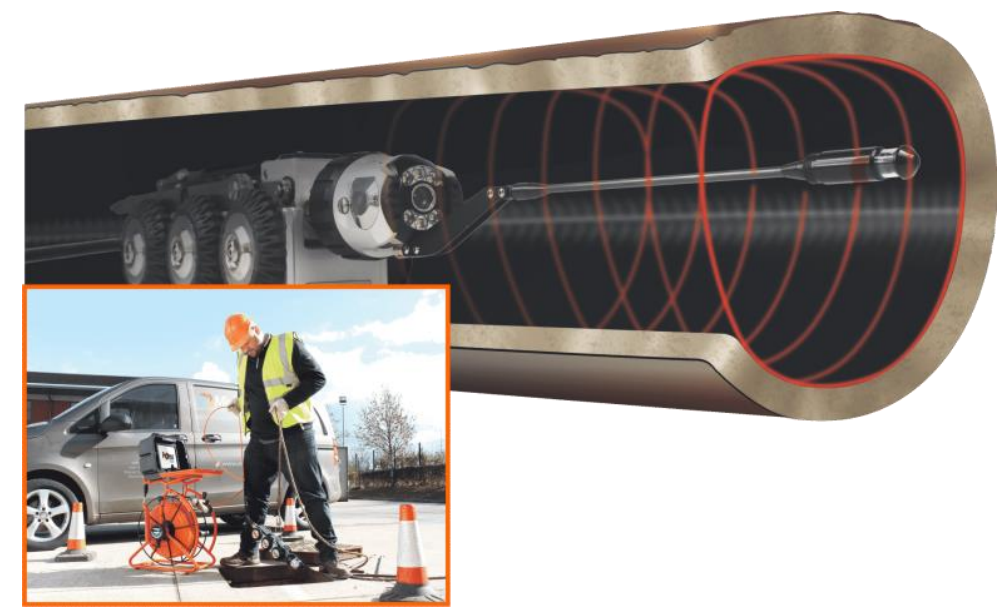

Figure 4 - Example of using lasers to monitor the internal condition of pipes

The disadvantage of this method is the necessity to put the inspected pipeline out of operation, since laser monitoring can only be carried out in dry sections of the pipeline. Video cameras or sonars are also usually used in combination with lasers. A brief summary of lasers is presented in Table 5.

Table 5 - Brief information on lasers

\begin{tabular}{cc}
\hline Pipe type & Self-flow lines, Mainline \\
\hline Piping material & Any \\
\hline Pipe size & Depends on the size of the device \\
\hline Detectable defects & Deformation, siltation, corrosion \\
\hline Advantages & $\begin{array}{c}\text { Relatively high scanning accuracy compared to cameras, the data can be } \\
\text { used to create a 3D model of the pipeline }\end{array}$ \\
\hline Disadvantages & Failure to detect defects in pipes filled with water \\
\hline
\end{tabular}

\subsection{Multicriteria analysis}

Due to the fact that all the solutions under consideration have different operating principles, devices and purposes, not all technical and economic parameters can be used in the multi-criteria analysis. For example, some monitoring systems can detect the location of cracks and leaks in the pipeline, but this study only considers defects related to well flooding and clogging.

For optimal selection of methods for monitoring sewer systems into a single symbiosis, all technical and economic parameters were combined into a single table (Table 6). These include such data as: measurement accuracy; cost; the maximum diameter of the investigated pipe; the type of pipeline. 
Table 6 - Technical and economic parameters of the devices

\begin{tabular}{|c|c|c|c|c|c|}
\hline 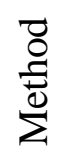 & Device & Accuracy & Pipe diameter & Pipe type* & Cost** \\
\hline \multirow{18}{*}{$\stackrel{\pi}{5}$} & CrystalCam & $60 \mathrm{~m}$ & up to $50 \mathrm{~mm}$ & Self-flow lines & $\$ 1250$ \\
\hline & Flexiprobe & $150 \mathrm{~m}$ & $25-200 \mathrm{~mm}$ & Self-flow lines & $\$ 1000$ \\
\hline & Hydrus & $50 \mathrm{~m}$ & up to $50 \mathrm{~mm}$ & Self-flow lines & $\$ 350$ \\
\hline & Orion & $50 \mathrm{~m}$ & up to $100 \mathrm{~mm}$ & Self-flow lines & $\$ 800$ \\
\hline & Orion L & $70 \mathrm{~m}$ & up to $100 \mathrm{~mm}$ & Self-flow lines & $\$ 850$ \\
\hline & Push Camera & $90 \mathrm{~m}$ & $25-300 \mathrm{~mm}$ & Self-flow lines & $\$ 6000$ \\
\hline & $\begin{array}{c}\text { IBAK LISY 150- } \\
\mathrm{M}\end{array}$ & $\sim 200 \mathrm{~m}$ & up to $150 \mathrm{~mm}$ & $\begin{array}{c}\text { Self-flow lines, partially } \\
\text { mainline }\end{array}$ & $\$ 12000$ \\
\hline & LAMP & $\sim 800 \mathrm{~m}$ & $150-600 \mathrm{~mm}$ & $\begin{array}{c}\text { Self-flow lines, partially } \\
\text { mainline }\end{array}$ & $\$ 3000$ \\
\hline & $\begin{array}{l}\text { Lateral Evaluation } \\
\text { Television System }\end{array}$ & $\sim 240 \mathrm{~m}$ & up to $200 \mathrm{~mm}$ & $\begin{array}{c}\text { Self-flow lines, partially } \\
\text { mainline }\end{array}$ & $\$ 850$ \\
\hline & $\begin{array}{l}\text { Lateral Inspection } \\
\text { System }\end{array}$ & $\sim 1000 \mathrm{~m}$ & $200-600 \mathrm{~mm}$ & $\begin{array}{c}\text { Self-flow lines, partially } \\
\text { mainline }\end{array}$ & $\$ 1000$ \\
\hline & ELK T100 Mini & $150 \mathrm{~m}$ & $100-250 \mathrm{~mm}$ & $\begin{array}{c}\text { Self-flow lines, } \\
\text { Mainline, Drainage } \\
\text { canals } \\
\end{array}$ & $\$ 1500$ \\
\hline & KRA 65 & $150 \mathrm{~m}$ & up to $100 \mathrm{~mm}$ & $\begin{array}{c}\text { Self-flow lines, } \\
\text { Mainline, Drainage } \\
\text { canals }\end{array}$ & $\$ 5000$ \\
\hline & $\begin{array}{l}\text { Mighty Mini } \\
\text { Transporter }\end{array}$ & $150 \mathrm{~m}$ & $100-300 \mathrm{~mm}$ & Self-flow lines & $\$ 2000$ \\
\hline & Rovver 100 & $200 \mathrm{~m}$ & $100-300 \mathrm{~mm}$ & Self-flow lines & $\$ 5000$ \\
\hline & Versatrax 100 & $180 \mathrm{~m}$ & up to $100 \mathrm{~mm}$ & $\begin{array}{c}\text { Self-flow lines, } \\
\text { Mainline, Drainage } \\
\text { canals } \\
\end{array}$ & $\$ 2250$ \\
\hline & $\begin{array}{l}\text { Xpress Silver- } \\
\text { Bullet Crawler }\end{array}$ & $180 \mathrm{~m}$ & $100-380 \mathrm{~mm}$ & Self-flow lines & $\$ 4620$ \\
\hline & $\begin{array}{c}\text { Versatrax } 300 \\
\text { VLR }\end{array}$ & $1828 \mathrm{~m}$ & up to $300 \mathrm{~mm}$ & Self-flow lines & $\$ 10000$ \\
\hline & Responder & $1600 \mathrm{~m}$ & up to $900 \mathrm{~mm}$ & $\begin{array}{l}\text { Self-flow lines, } \\
\text { Mainline }\end{array}$ & $\$ 15000$ \\
\hline \multirow{5}{*}{ 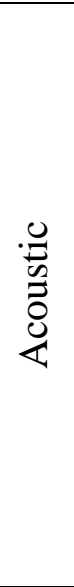 } & A-SIS & $0,8 \mathrm{~mm}$ & up to $300 \mathrm{~mm}$ & $\begin{array}{c}\text { Self-flow lines, } \\
\text { Mainline, Drainage } \\
\text { canals }\end{array}$ & $\$ 7500$ \\
\hline & Envirosight & $1 \mathrm{~mm}$ & up to $300 \mathrm{~mm}$ & Self-flow lines & $\$ 8000$ \\
\hline & PipeEye & $0,6 \mathrm{~mm}$ & up to $250 \mathrm{~mm}$ & $\begin{array}{l}\text { Self-flow lines, } \\
\text { Mainline }\end{array}$ & $\$ 9850$ \\
\hline & RVS2 & $0,5 \mathrm{~mm}$ & up to $250 \mathrm{~mm}$ & $\begin{array}{c}\text { Self-flow lines, } \\
\text { Mainline, Drainage } \\
\text { canals } \\
\end{array}$ & $\$ 15000$ \\
\hline & $\begin{array}{l}\text { Sonar Profiler } \\
\text { System }\end{array}$ & $0,5 \mathrm{~mm}$ & up to $300 \mathrm{~mm}$ & $\begin{array}{c}\text { Self-flow lines, } \\
\text { Mainline, Drainage } \\
\text { canals }\end{array}$ & $\$ 13200$ \\
\hline
\end{tabular}




\begin{tabular}{|c|c|c|c|c|c|}
\hline & $\begin{array}{l}\text { Sonar Sewer } \\
\text { Profiling } \\
\text { Attachment }\end{array}$ & $1,4 \mathrm{~mm}$ & up to $900 \mathrm{~mm}$ & $\begin{array}{l}\text { Self-flow lines, } \\
\text { Mainline }\end{array}$ & $\$ 5750$ \\
\hline & $\begin{array}{c}\text { Sonar Sweep } \\
\text { Attachment }\end{array}$ & $2 \mathrm{~mm}$ & up to $900 \mathrm{~mm}$ & $\begin{array}{c}\text { Self-flow lines, } \\
\text { Mainline }\end{array}$ & $\$ 7000$ \\
\hline \multirow{5}{*}{ 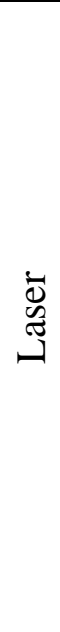 } & $\begin{array}{l}\text { Active 3D Laser } \\
\text { Scanning }\end{array}$ & $2 \mathrm{~mm}$ & $1200-2500 \mathrm{~mm}$ & $\begin{array}{l}\text { Self-flow lines, } \\
\text { Mainline }\end{array}$ & $\$ 7700$ \\
\hline & Coolvision & $0,5 \mathrm{~mm}$ & $100-2500 \mathrm{~mm}$ & $\begin{array}{c}\text { Self-flow lines, } \\
\text { Mainline }\end{array}$ & $\$ 10000$ \\
\hline & $\begin{array}{c}\text { Laser Profiler - } \\
\text { CUES }\end{array}$ & $0,3 \mathrm{~mm}$ & $150-1800 \mathrm{~mm}$ & $\begin{array}{c}\text { Self-flow lines, } \\
\text { Mainline, Drainage } \\
\text { canals }\end{array}$ & $\$ 15000$ \\
\hline & $\begin{array}{l}\text { Laser Profiling } \\
\text { Tool }\end{array}$ & $1 \mathrm{~mm}$ & $100-4000 \mathrm{~mm}$ & $\begin{array}{c}\text { Self-flow lines, } \\
\text { Mainline, Drainage } \\
\text { canals } \\
\end{array}$ & $\$ 10000$ \\
\hline & $\begin{array}{l}\text { Laser Profiler - } \\
\text { R\&R Visual }\end{array}$ & $1,5 \mathrm{~mm}$ & $150-4000 \mathrm{~mm}$ & $\begin{array}{l}\text { Self-flow lines, } \\
\text { Mainline, Drainage } \\
\text { canals }\end{array}$ & $\$ 12000$ \\
\hline
\end{tabular}

** The cost is per set

In order to objectively compare sewer monitoring solutions according to the identified criteria, it is necessary to perform data normalization. The value of each criterion is divided by the sum of all values in a particular criterion. The final sum of values after normalization should be equal to 1 .

Each criterion was then given a weight. Each criterion was weighted by the following logic: "Accuracy" criterion will have the biggest weight $(0,4)$ because it is the most important factor for any measuring device; "Pipe diameter" criterion will have the weight of 0,3 because the pipe diameter plays big part in measurement accuracy; "Type of pipeline" criterion will have the weight of 0,2 because not all the solutions considered are applicable for the specific type of the pipeline; "Cost" criterion will have the smallest weight $(0,1)$ because high cost of the equipment can be justified by the accuracy of the measurement

Based on the weights for each criterion several combinations (symbioses) of devices will be selected. For convenience, all normalized values for each criterion were highlighted using color scales, where the darkest color corresponds to the highest value, and the lightest - the lowest.

The final result will be a few of the most optimal combinations of solutions for sewer monitoring.

\section{Results and Discussion}

The normalized data were sorted based on the parameters of the weights for each criterion (Tables 7-9). The devices with the maximum values for each criterion, taking into account the selection by weights, are displayed at the beginning of the list. Thus, the best solutions were obtained for each of the three presented monitoring methods.

Table 7 - Data normalization for visual observation methods

\begin{tabular}{ccccc}
\hline Device & Accuracy & Pipe diameter & Pipe type & Cost \\
\hline Criterion weight & 0,4 & 0,3 & 0,2 & 0,1 \\
\hline Versatrax 300 VLR & 0,25573587 & 0,071770335 & 0,037037037 & 0,137988133 \\
\hline Responder & 0,223838836 & 0,215311005 & 0,074074074 & 0,2069822 \\
\hline Lateral Inspection System & 0,139899273 & 0,09569378 & 0,055555556 & 0,013798813 \\
\hline
\end{tabular}




\begin{tabular}{ccccc}
\hline & & & & \\
\cline { 2 - 5 } LAMP & 0,111919418 & 0,107655502 & 0,055555556 & 0,04139644 \\
\hline $\begin{array}{c}\text { Lateral Evaluation } \\
\text { Television }\end{array}$ & 0,033575825 & 0,04784689 & 0,055555556 & 0,011728991 \\
\hline Rovver 100 & 0,027979855 & 0,04784689 & 0,037037037 & 0,068994067 \\
\hline IBAK LISY 150-M & 0,027979855 & 0,035885167 & 0,055555556 & 0,16558576 \\
\hline $\begin{array}{c}\text { Xpress Silver-Bullet } \\
\text { Crawler }\end{array}$ & 0,025181869 & 0,066985646 & 0,037037037 & 0,063750517 \\
\hline Versatrax 100 & 0,025181869 & 0,023923445 & 0,111111111 & 0,03104733 \\
\hline Mighty Mini Transporter & 0,020984891 & 0,04784689 & 0,037037037 & 0,027597627 \\
\hline Flexiprobe & 0,020984891 & 0,041866029 & 0,037037037 & 0,013798813 \\
\hline ELK T100 Mini & 0,020984891 & 0,035885167 & 0,111111111 & 0,02069822 \\
\hline KRA 65 & 0,020984891 & 0,023923445 & 0,111111111 & 0,068994067 \\
\hline Push Camera & 0,012590935 & 0,065789474 & 0,037037037 & 0,08279288 \\
\hline Orion L & 0,009792949 & 0,023923445 & 0,037037037 & 0,011728991 \\
\hline CrystalCam & 0,008393956 & 0,011961722 & 0,037037037 & 0,017248517 \\
\hline Orion & 0,006994964 & 0,023923445 & 0,037037037 & 0,011039051 \\
\hline Hydrus & 0,006994964 & 0,011961722 & 0,037037037 & 0,004829585 \\
\hline TOTAL & 1 & 1 & 1 & 1 \\
\hline
\end{tabular}

Table 8 - Data normalization for acoustic methods

\begin{tabular}{ccccc}
\hline Device & Accuracy & Pipe diameter & Pipe type & Cost \\
\hline Criterion weight & 0,4 & 0,3 & 0,2 & 0,1 \\
\hline Active 3D Laser Scanning & 0,526315789 & 0,140540541 & 0,2 & 0,180327869 \\
\hline Laser Profiling Tool & 0,263157895 & 0,421621622 & 0,3 & 0,234192037 \\
\hline Coolvision & 0,131578947 & 0,259459459 & 0,2 & 0,234192037 \\
\hline Laser Profiler - CUES & 0,078947368 & 0,178378378 & 0,3 & 0,351288056 \\
\hline TOTAL & 1 & 1 & 1 & 1 \\
\hline
\end{tabular}

Table 9 - Data normalization for laser scanning methods

\begin{tabular}{ccccc}
\hline Device & Accuracy & Pipe diameter & Pipe type & Cost \\
\hline Criterion weight & 0,4 & 0,3 & 0,2 & 0,1 \\
\hline Sonar Sweep Attachment & 0,294117647 & 0,28125 & 0,125 & 0,105580694 \\
\hline Sonar Sewer Profiling & 0,205882353 & 0,28125 & 0,125 & 0,086726998 \\
\hline Envirosight & 0,147058824 & 0,09375 & 0,0625 & 0,12066365 \\
\hline A-SIS & 0,117647059 & 0,09375 & 0,1875 & 0,113122172 \\
\hline PipeEye & 0,088235294 & 0,078125 & 0,125 & 0,148567119 \\
\hline Sonar Profiler System & 0,073529412 & 0,09375 & 0,1875 & 0,199095023 \\
\hline RVS2 & 0,073529412 & 0,078125 & 0,1875 & 0,226244344 \\
\hline TOTAL & 1 & 1 & 1 & 1 \\
\hline
\end{tabular}

As mentioned earlier, each of the methods separately does not allow an objective assessment of the internal condition of pipelines due to various factors. The optimal solution can be considered the application of several methods at the same time in order to compensate the disadvantages of one of them. Based on this logic, five combinations of solutions including several monitoring methods were built (Figure 5). 


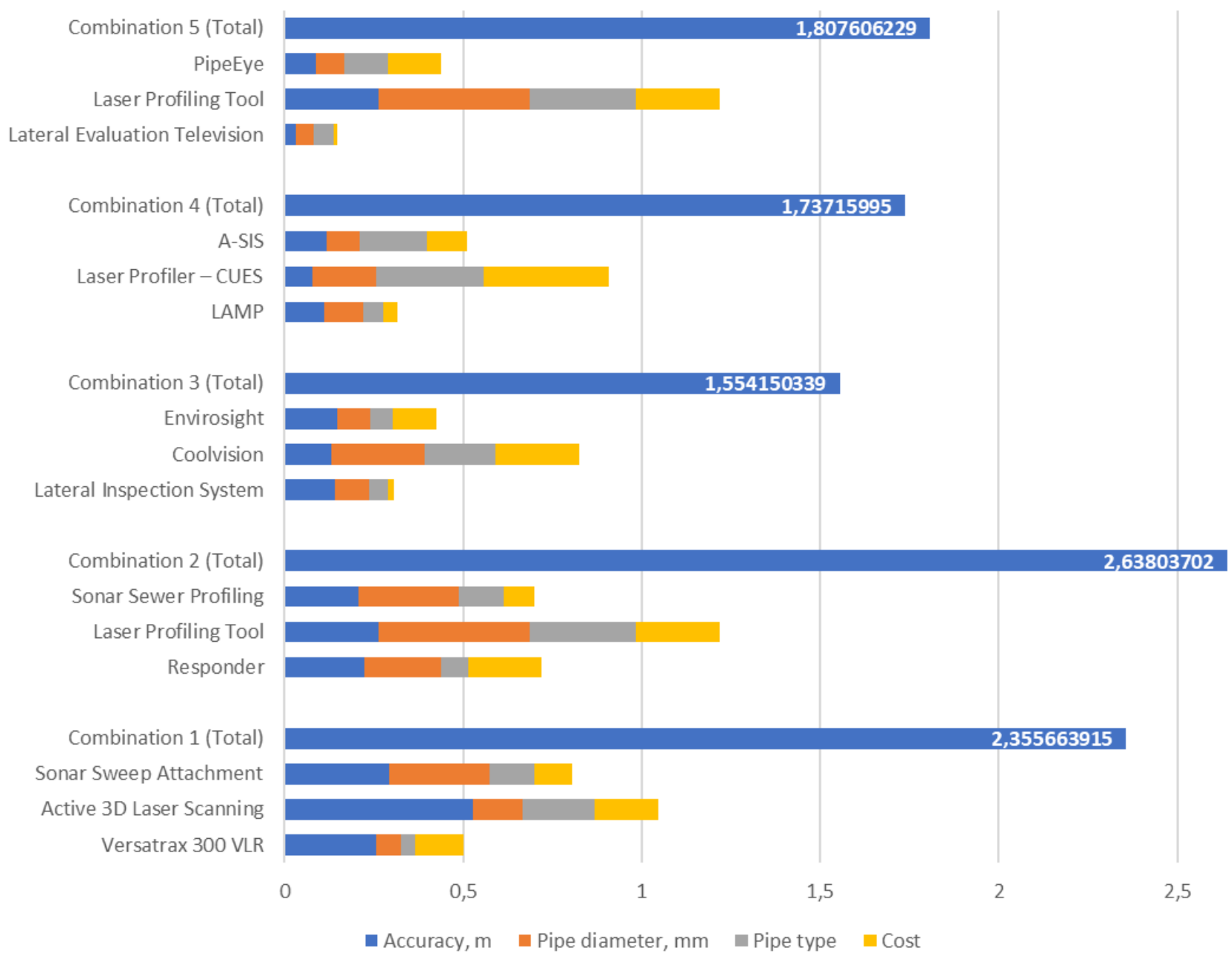

Figure 5 - Analysis of the technical and economic performance of the proposed combinations

As can be seen, the combination of solutions No. 2 has the highest score for each criterion 2.638. The methods of this combination allow monitoring of large diameter pipes with relatively high measurement accuracy.

Combination No. 1 scored slightly lower than combination No. $2-2.355$. The methods of this combination allow monitoring of medium and small diameter pipes with a relatively high degree of accuracy.

In general, the two combinations described above can be recommended as basic methods of sewer monitoring. Compared to the other suggested combinations, they have the best price/performance ratio.

In the case of gravity and wastewater lines, combination No. 1 is recommended because it is best suited for pipes of medium and small diameter (100 mm to $1300 \mathrm{~mm})$. For main sewer lines the most suitable solution is combination No.2 (for pipes with a diameter of $900 \mathrm{~mm}$ to $3900 \mathrm{~mm}$ ).

\section{Conclusions}

In this article, a multi-criteria analysis of methods for monitoring the internal condition of sewers was performed. As a result, the following conclusions can be made:

1. Many factors influence the choice of equipment: technical characteristics of the equipment itself; diameter of the pipeline; material of which the pipeline is made; availability of convenient access to the inspected area.

2. In some conditions, one method of monitoring is not enough to determine an accurate picture of the internal condition of the pipeline, so it is recommended to use a symbiosis of several devices, combined into a single system suitable for a particular case. 
3. In general, the use of one or another symbiosis of solutions depends primarily on the amount of available funds on the balance of the city. Not always the most expensive methods can guarantee the quality of the final results. Often in the choice of one or another equipment it is necessary to find the optimal balance between price and quality. proposed.

4. After the analysis, two most optimal combinations of solutions for sewer monitoring were

\section{Acknowledgments}

This study was funded by the Committee of Science of the Ministry of Education and Science of the Republic of Kazakhstan (Grant No. AP09057970).

\section{References}

1. A Review on Inspection Methods of Sewer Pipelines / T. Azizzadeh, M. Riahi - 2019. - Vol. 2. - P. 9-20.

2. The relevance of sewer deterioration modelling to support asset management strategies / N. Caradot, H. Sonnenberg, I. Kropp, A. Ringe, S. Denhez, A. Hartmann, P. Rouault // Urban Water Journal. — 2017. — Vol. 14, No. 10. — P. 1007-1015. https://doi.org/10.1080/1573062X.2017.1325497

3. An economic loss model for failure of sewer pipelines / M. Elmasry, A. Hawari, T. Zayed // Structure and Infrastructure Engineering. $-2018 . \quad-\quad$ Vol. 14, No. $10 . \quad$ - $\quad$ P. $1312-1323$. https://doi.org/10.1080/15732479.2018.1433693

4. The threat of carbapenem-resistant bacteria in the environment: Evidence of widespread contamination of reservoirs at a global scale / M.C. Mills, J. Lee // Environmental Pollution. - 2019. — Vol. 255. — P. 113143. https://doi.org/10.1016/j.envpol.2019.113143

5. World Urbanization Prospects 2018: Population studies. — New York, USA: United Nations, 2018.

6. Acoustic and ultrasonic techniques for defect detection and condition monitoring in water and sewerage pipes: A review / Y. Yu, A. Safari, X. Niu, B. Drinkwater, K.V. Horoshenkov // Applied Acoustics. — 2021. — Vol. 183. — P. 108282. https://doi.org/10.1016/j.apacoust.2021.108282

7. An assessment - water quality monitoring practices and sewer robotic systems / S. Ansari, S.M. Khairnar, R.R. Patil, R.S. Kokate // INFORMATION TECHNOLOGY IN INDUSTRY. - 2021. — Vol. 9, No. 1. — P. $140-148$. https://doi.org/10.17762/itii.v9i1.113

8. Automated defect classification in sewer closed circuit television inspections using deep convolutional neural networks / S.S. Kumar, D.M. Abraham, M.R. Jahanshahi, T. Iseley, J. Starr // Automation in Construction. - 2018. — Vol. 91. - P. 273-283. https://doi.org/10.1016/j.autcon.2018.03.028

9. Automatic Detection and Classification of Sewer Defects via Hierarchical Deep Learning / Q. Xie, D. Li, J. Xu, Z. Yu, J. Wang // IEEE Transactions on Automation Science and Engineering. — 2019. — Vol. 16, No. 4. — P. 18361847. https://doi.org/10.1109/TASE.2019.2900170

10. Inspection methods for sewer pipes / T. Lampola, S. Kuikka2018.

11. Detection of extraneous water ingress into the sewer system using tandem methods - a case study in Trondheim city / M. Beheshti, S. Sægrov // Water Science and Technology. — 2019. — Vol. 79, No. 2. — P. 231-239. https://doi.org/10.2166/wst.2019.057

12. Realtime Monitoring of Underground Sewage System using GPRS IoT Module / R. Siddharth, S. Selvapparithi, R. Raman, S. Kumar - 2019. — Vol. 9. - C. 20431-20433.

13. Review on Computer Aided Sewer Pipeline Defect Detection and Condition Assessment / S. Moradi, T. Zayed, F. Golkhoo // Infrastructures. - 2019. — Vol. 4, No. 1. — P. 10. https://doi.org/10.3390/infrastructures4010010

14. Influence of Computer Vision and IoT for Pipeline Inspection-A Review / N. Mangayarkarasi, G. Raghuraman, S. Kavitha // 2019 International Conference on Computational Intelligence in Data Science (ICCIDS)2019. — P. 1-6. https://doi.org/10.1109/ICCIDS.2019.8862109

15. Sewer Life Span Prediction: Comparison of Methods and Assessment of the Sample Impact on the Results / T. Laakso, T. Kokkonen, I. Mellin, R. Vahala // Water. - 2019. — Vol. 11, No. 12. - P. 2657. https://doi.org/10.3390/w11122657

16. Sewer damage detection from imbalanced CCTV inspection data using deep convolutional neural networks with hierarchical classification / D. Li, A. Cong, S. Guo // Automation in Construction. — 2019. — Vol. 101. — P. 199208. https://doi.org/10.1016/j.autcon.2019.01.017

17. Learning and SLAM Based Decision Support Platform for Sewer Inspection / T.-Y. Chuang, C.-C. Sung // Remote Sensing. - 2020. — Vol. 12, No. 6. - P. 968. https://doi.org/10.3390/rs12060968

18. Sewer inspection with CCTV, Smoke and Dye test in Kosovo / S. Bublaku // UBT International Conference. 2020.

19. Automated Vision Systems for Condition Assessment of Sewer and Water Pipelines / R. Rayhana, Y. Jiao, A. Zaji, Z. Liu // IEEE Transactions on Automation Science and Engineering. — 2021. — Vol. 18, No. 4. - C. 1861-1878. https://doi.org/10.1109/TASE.2020.3022402 
20. Measurement of Wastewater Discharge in Sewer Pipes Using Image Analysis / H.W. Ji, S.S. Yoo, B.-J. Lee, D.D. Koo, J.-H. Kang // Water. — 2020. — Vol. 12, No. 6. - P. 1771. https://doi.org/10.3390/w12061771

21. Empirical Modeling of Acoustic Signal Attenuation in Municipal Sewer Pipes for Condition Monitoring Applications / M.S. Khan // 2018 IEEE Green Technologies Conference (GreenTech). — Austin, TX: IEEE, 2018. - C. 137-143. https://doi.org/10.1109/GreenTech.2018.00033

22. A technology for sewer pipe inspection (Part 2): Experimental assessment of a new laser profiler for sewer defect detection and quantification / M. Lepot, N. Stanić, F.H.L.R. Clemens // Automation in Construction. — 2017. Vol. 73. - P. 1-11. https://doi.org/10.1016/j.autcon.2016.10.010

\section{Information about authors:}

Yelbek Utepov - Assoc. Prof. PhD, Acting Professor, Department of Structural Engineering, L.N. Gumilyov Eurasian National University, Nur-Sultan, Kazakhstan, utepov-elbek@ mail.ru Alizhan Kazkeyev - PhD Student, Department of Structural Engineering, L.N. Gumilyov Eurasian National University, Nur-Sultan, Kazakhstan, alizhan7sk@ gmail.com

Aleksej Aniskin - PhD, Assistant Professor, Department of Civil Engineering, University North, Varaždin, Croatia, aaniskin@unin.hr 